\title{
Clinical Practice Guideline for the Management of Antithrombotic Agents in Patients Undergoing Gastrointestinal Endoscopy
}

\author{
Hyun Lim ${ }^{1 *}$, Eun Jeong Gong ${ }^{2^{*}}$, Byung-Hoon Min ${ }^{3}$, Seung Joo Kang ${ }^{4}$, Cheol Min Shin ${ }^{5}$, Jeong-Sik Byeon ${ }^{6}$, Miyoung Choi ${ }^{7}$, Chan \\ Guk Park ${ }^{8}$, Joo Young Cho ${ }^{9}$, Soo Teik Lee ${ }^{10}$, Ho Gak Kim ${ }^{11}$ and Hoon Jai Chun ${ }^{12}$ \\ ${ }^{1}$ Department of Gastroenterology, Hallym University Sacred Heart Hospital, Anyang, ${ }^{2}$ Department of Internal Medicine, Gangneung \\ Asan Hospital, University of Ulsan College of Medicine, Gangneung, ${ }^{3}$ Department of Gastroenterology, Samsung Medical Center, \\ Seoul, ${ }^{4}$ Department of Internal Medicine, Seoul National University Hospital Healthcare System Gangnam Center, Seoul, ${ }^{5}$ Department \\ of Internal Medicine, Seoul National University Bundang Hospital, Seongnam, ${ }^{6}$ Department of Gastroenterology, Asan Medical \\ Center, Seoul, ${ }^{7}$ National Evidence-based Healthcare Collaborating Agency, Seoul, ${ }^{8}$ Department of Gastroenterology, Chosun \\ University Hospital, Gwangju, ${ }^{9}$ Department of Gastroenterology, Cha University Bundang Medical Center, Seongnam, ${ }^{10}$ Department of \\ Gastroenterology, Jeonbuk National Hospital, Jeonju, ${ }^{11}$ Department of Gastroenterology, Daegu Catholic University School of Medicine, \\ Daegu, ${ }^{12}$ Department of Gastroenterology, Korea University Anam Hospital, Seoul, Korea
}

Antithrombotic agents, including antiplatelet agents and anticoagulants, are increasingly used in South Korea. The management of patients using antithrombotic agents and requiring gastrointestinal endoscopy is an important clinical challenge. Although clinical practice guidelines (CPGs) for the management of patients receiving antithrombotic agents and undergoing gastrointestinal endoscopy have been developed in the Unites States, Europe, and Asia Pacific region, it is uncertain whether these guidelines can be adopted in South Korea. After reviewing current CPGs, we identified unmet needs and recognized significant discrepancies in the clinical practice among regions. This is the first CPG in Korea providing information that may assist endoscopists in the management of patients on antithrombotic agents who require diagnostic or elective therapeutic endoscopy. This guideline was developed through the adaptation process as an evidence-based method, with four guidelines retrieved by systematic review. Eligible guidelines were evaluated according to the Appraisal of Guidelines for Research and Evaluation II process, and 13 statements were established using a grading system. This guideline was reviewed by external experts before an official. It will be revised as necessary to cover changes in technology, evidence, or other aspects of clinical practice. Clin Endosc 2020;53:663-677

Key Words: Adaptation; Anticoagulants; Antiplatelet agents; Endoscopy; Guidelines

\section{INTRODUCTION}

Antithrombotic agents, including antiplatelet agents and anticoagulants, are actively used in clinical practice for primary and secondary prevention of cardio-cerebrovascular disease. ${ }^{1-4}$ To date, various types of antiplatelet agents and anticoagulants have been developed, and new agents such as non-vitamin $\mathrm{K}$ antagonist oral anticoagulants (NOAC) are also being devel-

\footnotetext{
Received: July 15, 2020 Revised: September 7, 2020

Accepted: September 8, 2020

Correspondence: Seung Joo Kang

Department of Internal Medicine, Seoul National University Hospital Healthcare System Gangnam Center, 152 Teheran-ro, Gangnam-gu, Seoul 06236, Korea Tel: +82-2-2112-5772, Fax: +82-2-2112-5794, E-mail: ksjoo55@naver.com

ORCID: https://orcid.org/0000-0002-7401-8356

Cheol Min Shin

Department of Internal Medicine, Seoul National University Bundang Hospital, 82 Gumi-ro 173 Beon-gil, Bundang-gu, Seongnam 13620, Korea

Tel: +82-31-787-7057, Fax: +82-31-787-4052, E-mail: scm6md@gmail.com

ORCID: https://orcid.org/0000-0003-2265-9845

*These authors contributed equally to this study.

These guideline is being co-published in Clinical Endoscopy (in English) and the Korean Journal of Gastroenterology (in Korean) for the facilitated distribution.
}

(cc) This is an Open Access article distributed under the terms of the Creative Commons Attribution Non-Commercial License (http://creativecommons.org/licenses/by$\mathrm{nc} / 3.0$ ) which permits unrestricted non-commercial use, distribution, and reproduction in any medium, provided the original work is properly cited. 
oped and released. With the aging of the population, the number of patients suffering from cardio-cerebrovascular disease and associated conditions is increasing in South Korea. Therefore, the number of patients receiving antithrombotic agents has increased in clinical practice.

Recent advances in equipment and techniques for endoscopy have enabled a wide range of endoscopic procedures for both diagnostic and therapeutic purposes. South Korea is a region with the highest incidence of gastric cancer in the world. Since the introduction of the National Cancer Screening Program, more than two-thirds of gastric cancers are diagnosed at an early stage, and nearly half of these patients are being treated with endoscopic resection. ${ }^{5-7}$ Generally, the incidence of adverse events such as bleeding associated with diagnostic endoscopy is very low. In contrast, therapeutic endoscopic procedures have a higher risk of adverse events compared to diagnostic endoscopic procedures, and the use of antithrombotic agents can further increase the risk of adverse events. Decisions regarding the management of antithrombotic agents prior to endoscopic procedures should be made following a comprehensive assessment of the risk of thromboembolism due to the discontinuation of antithrombotic agents along with the risk of bleeding associated with endoscopic procedures. ${ }^{8,9}$

Depending on the region and race, clinically available endoscopic instruments, endoscopic procedures, and risk of adverse events associated with endoscopic procedures may differ. The risk of developing thromboembolism caused by the discontinuation of antithrombotic agents also varies depending on the region and race. Therefore, clinical practice guidelines (CPGs) regarding the use of antithrombotic agents before and after endoscopic procedures should reflect local medical environments, and several guidelines have been developed till date. ${ }^{10-13}$ Nevertheless, such guidelines have not yet been developed for the South Korean population. Given that it is uncertain whether the available CPGs will be suitable for patients in South Korea, we developed a guideline for the management of antithrombotic agents during the peri-endoscopic period. In addition to a comprehensive review of the literature, particular concerns were considered to develop a guideline that reflects the characteristics of epidemiology, clinical practice patterns, and medical resources in South Korea.

\section{METHODS}

\section{Purpose and scope of clinical practice guideline}

This CPG aimed to provide information on the management of antithrombotic agents during the peri-endoscopic period, based on a comprehensive review of current evidence and CPGs regarding bleeding and thromboembolic adverse events associated with endoscopic procedures in patients receiving antithrombotic agents. This CPG refers to adult patients who are taking antithrombotic agents for primary or secondary prevention of cardio-cerebrovascular disease and undergo diagnostic or elective therapeutic endoscopic procedures, excluding emergency endoscopic procedures such as endoscopic hemostasis. The target readers of this CPG are gastroenterologists who perform endoscopic procedures in primary, secondary, and tertiary care institutions. The CPG is intended to assist gastroenterologists in making decisions for appropriate treatments regarding the use of antithrombotic agents before and after endoscopic procedures. In addition, it aims to serve as a guide for resident physicians and healthcare workers, and to provide practical information for patients and the general public.

\section{Organization of the clinical practice guideline committee and development process}

The CPG committee including the former chairperson (Hoon Jai Chun), the former president (Soo Teik Lee and Ho Gak Kim), and executive committee members of the Korean Society of Gastrointestinal Endoscopy (KSGE), convened in November 2017. The members of the CPG committee established a strategy for the development of the CPG, appointed a director of the CPG project, and reviewed and approved the budget for this project. They reviewed suggested recommendations and ensured the editorial independence and participation of all parties involved in the development process. In March 2020, the CPG committee (the chairperson of the board of the KSGE, Joo Young Cho; the president of KSGE, Chan Guk Park; and the executive committee members of KSGE) reviewed the final version of the CPG and authorized its implementation.

The CPG committee organized the KSGE Task Force on CPG, which supervised the development of the CPG regarding the use of antithrombotic agents before and after endoscopic procedures. For the development of the CPG, Jeong-Sik Byeon, a board-certified gastroenterologist and the member of KSGE, was appointed as the director of the KSGE Task Force on CPG, and five other gastroenterologists (Seung Joo Kang, Eun Jeong Gong, Byung-Hoon Min, Cheol Min Shin, and Hyun Lim) participated as members of the KSGE Task Force on CPG. A CPG development methodology expert (Miyoung Choi) from the National Evidence-based Healthcare Collaborating Agency (NECA) collaborated on the development of the guideline. The KSGE Task Force on CPG selected key questions, conducted literature search, established recommendations, and drafted and revised the guideline.

The KSGE Task Force on CPG held a total of four meetings since December 22, 2017. The KSGE Task Force on CPG also 
held two workshops to set up a methodology for the development of the guideline and to review the development process (March 12, 2018 and November 10, 2018). These workshops involved training sessions on the methods of guideline development, grading of recommendation and level of evidence, and achievement of recommendation consensus. The KSGE Task Force on CPG chose the adaptation process and developed the CPG through online and face-to-face meetings.

\section{Selection of the key questions}

Selection criteria were made, and a questionnaire was developed through the population, intervention, comparison, outcome (PICO) process wherein key questions to be included in the $\mathrm{CPG}$ were derived. $\mathrm{P}$ (population) represents patients who have undergone diagnostic or elective therapeutic endoscopic procedures while taking antithrombotic agents, I (intervention) represents the interruption or replacement of antithrombotic agents during the peri-endoscopic period, C (comparison) includes the comparison group, which continues to use antithrombotic agents before and after endoscopic procedures, and $\mathrm{O}$ (outcome) represents the risk for the occurrence of adverse events associated with endoscopic procedures such as bleeding and thromboembolism. The members of the KSGE Task Force on CPG gathered key questions and specified the priority of each question to determine which questions were to be included in the CPG.

\section{Literature search and selection of existing guidelines for adaptation}

In May 2018, a literature search according to the key questions was performed using Ovid MEDLINE, KoreaMed, KoMGI, National Guideline Clearinghouse, and Guidelines International Network. The search index words included a combination of terms related to endoscopic procedures ("endoscopy" OR "esophagogastroduodenoscopy" OR "colonoscopy" OR "endosonography" OR "endoscopic retrograde cholangiopancreatography" OR "enteroscopy" OR "biopsy" OR "stent" OR "argon plasma coagulation" OR "papillary balloon dilation" OR "sphincterotomy" OR "fine needle aspiration" OR "percutaneous endoscopic gastrostomy" OR "ampullectomy" OR "cystgastrotomy" OR "pneumatic dilation" OR "polypectomy" OR "endoscopic mucosal resection" OR "endoscopic submucosal dissection"), terms related to antithrombotic agents ("antiplatelet" OR "platelet aggregation inhibitor" OR "aspirin" OR "acetylsalicylic acid" OR "thienopyridine" OR "clopidogrel" OR "prasugrel" OR "ticagrelor" OR "ticlopidine" OR "cilostazol" OR "triflusal" OR "anticoagulants" OR "warfarin" OR "coumadin" OR "heparin" OR "low molecular weight heparin" OR "enoxaparin" OR "dalteparin" OR "nadroparin" OR "non-vitamin K antagonist oral anticoagulant" OR "novel oral

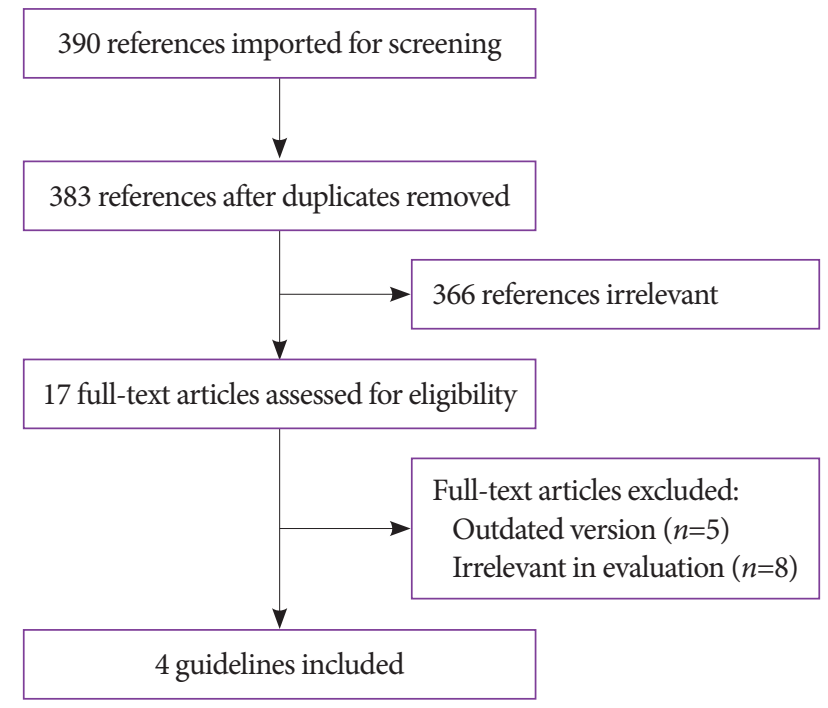

Fig. 1. Flowchart of guideline selection for adaptation process.

anticoagulant" OR "direct oral anticoagulant" OR "dabigatran" OR "apixaban" OR "rivaroxaban" OR "enoxaban" OR "bridge therapy" OR "antithrombin"), and terms related to CPG ("guideline" OR "recommendation" OR "practice guideline").

The criteria for selecting existing CPGs for adaptation were as follows: (1) it should be evidence-based; (2) it should be published in Korean or English; (3) it should be presented between January 2000 and May 2018; (4) it should be a CPG for adults aged 19 years and above; (5) it should be the latest edition, if there are revised editions; and (6) it should be a CPG with external review and expert consensus. The exclusion criteria were as follows: (1) a CPG without a clear declaration of recommendations and evidence supporting recommendations; (2) an old edition of CPG that was a publication of a revised edition; and (3) a CPG developed by the adaptation process. Finally, four CPGs were selected for the evaluation and development of CPG (Fig. 1). ${ }^{10-13}$

For an update of the latest literature, studies published after 2016 were searched by combining and modifying search index words according to the key questions using MEDLINE and KoreaMed. The literature search was performed by a researcher working with the NECA, Miyoung Choi, and duplicate studies generated by cross searches among search engines were manually excluded. Two members were assigned to each key question, and they independently selected the literatures according to the established criteria. First, literature inappropriate for CPG development was eliminated by reviewing the titles and abstracts. In the case of studies not eliminated in this process, the decision to eliminate or select them was finalized after reviewing the entire study. In cases of disagreement be- 
tween two members, study selection was determined by consensus. If consensus was not reached, the team leader made the final decision. The exclusion criteria for the latest literature were as follows: (1) studies not targeting humans; (2) studies not targeting patients relevant to the key questions; (3) studies not conducting interventions and comparative interventions related to the key questions; (4) studies presented only as abstracts, case reports, or reviews; (5) studies not published in Korean or English; and (6) studies that did not provide the original text. If there was an overlap of the study populations between studies, the one with the smaller size was excluded.

\section{Risk of bias assessment, summary of evidence, and grade of recommendation}

The quality of CPGs, which are subject to adaptation, was evaluated using the Appraisal of Guidelines for Research and Evaluation (AGREE) II. The AGREE II consists of 23 structured key items organized within six domains followed by two global assessment items. ${ }^{14}$ Each of the AGREE II items are rated on a 7-point scale: 1 , strongly disagree, to 7 , strongly agree. Each of the selected CPGs was evaluated by three assessors, and a workshop for practicing and understanding AGREE II was held by a CPG development methodology expert, Miyoung Choi, to minimize inter-rater variability. Finally, four guidelines were selected based on the comparison of standardized scores of each category. ${ }^{10-13}$

In addition to CPGs, validity of selected recent studies was assessed using consistent and systematic methods. The randomized comparative studies were evaluated using the Cochrane Risk of Bias, ${ }^{15}$ whereas the non-randomized stud-

Table 1. Summary and Strength of Recommendations

\begin{tabular}{|c|c|c|}
\hline Statements & $\begin{array}{l}\text { Grade of rec- } \\
\text { ommendation }\end{array}$ & $\begin{array}{l}\text { Level of } \\
\text { evidence }\end{array}$ \\
\hline $\begin{array}{l}\text { Statement } 1 \text {. We do not recommend discontinuation of antiplatelet agents before low-risk endoscopic proce- } \\
\text { dures in patients taking one kind of antiplatelet agent. }\end{array}$ & Strong & Moderate \\
\hline $\begin{array}{l}\text { Statement } 2 \text {. We do not recommend discontinuation of aspirin before high-risk endoscopic procedures in } \\
\text { patients taking aspirin. For ultra-high-risk endoscopic procedures such as endoscopic mucosal resection for } \\
\text { large colon polyps }(\geq 2 \mathrm{~cm}) \text { and endoscopic submucosal dissection, withholding aspirin before the proce- } \\
\text { dures could be considered, depending on the risk of bleeding and thromboembolism. }\end{array}$ & Strong & Moderate \\
\hline $\begin{array}{l}\text { Statement 3. We recommend withholding P2Y12 receptor inhibitors (clopidogrel, ticlopidine, prasugrel, and } \\
\text { ticagrelor) 5-7 days before high-risk endoscopic procedures. }\end{array}$ & Strong & Moderate \\
\hline $\begin{array}{l}\text { Statement } 4 \text {. We suggest resuming P2Y12 receptor inhibitors as soon as possible once adequate hemostasis } \\
\text { has been achieved. }\end{array}$ & Weak & Low \\
\hline $\begin{array}{l}\text { Statement } 5 \text {. In patients on dual antiplatelet therapy, we do not recommend withholding both antiplatelet } \\
\text { agents before low-risk endoscopic procedures. }\end{array}$ & Weak & Low \\
\hline $\begin{array}{l}\text { Statement } 6 \text {. In patients on dual antiplatelet therapy, we recommend withholding P2Y12 receptor inhibitors } \\
5 \text {-7 days before high-risk endoscopic procedures. For ultra-high-risk endoscopic procedures, such as endo- } \\
\text { scopic mucosal resection for large colon polyps }(\geq 2 \mathrm{~cm}) \text { and endoscopic submucosal dissection, withholding } \\
\text { both antiplatelet agents before procedures could be considered depending on the risk of bleeding and throm- } \\
\text { boembolism. }\end{array}$ & Strong & Moderate \\
\hline $\begin{array}{l}\text { Statement 7. In patients on dual antiplatelet therapy, we suggest resuming P2Y12 receptor inhibitors as soon } \\
\text { as possible once adequate hemostasis has been achieved. }\end{array}$ & Weak & Low \\
\hline Statement 8 . We do not recommend withholding warfarin before low-risk endoscopic procedures. & Weak & Low \\
\hline $\begin{array}{l}\text { Statement } 9 . \text { We suggest withholding warfarin } 3-5 \text { days before high-risk endoscopic procedures. Heparin } \\
\text { bridging therapy is recommended in patients with high thromboembolic risk. }\end{array}$ & Weak & Low \\
\hline Statement 10 . We suggest resuming warfarin as soon as possible once adequate hemostasis has been achieved. & Weak & Low \\
\hline Statement 11 . We do not recommend discontinuation of NOAC before low-risk endoscopic procedures & Weak & Low \\
\hline Statement 12. We recommend withholding NOAC more than $48 \mathrm{hr}$ before high-risk endoscopic procedures. & Strong & Low \\
\hline Statement 13 . We suggest resuming NOAC once adequate hemostasis has been achieved. & Weak & Low \\
\hline
\end{tabular}

NOAC, non-vitamin $\mathrm{K}$ antagonist oral anticoagulants. 
ies were evaluated using Risk of Bias Assessment tool for Non-randomised Study (RoBANS) 2.0. ${ }^{16}$ Systematic reviews were evaluated using A MeaSurement Tool to Assess systematic Reviews (AMSTAR). ${ }^{17}$ The summary of evidence was determined using the Grading of Recommendations, Assessment, Development and Evaluation (GRADE) method. ${ }^{18}$ Randomized comparative studies were defined as having a high level of evidence, and observational studies were defined as having a low level of evidence. However, the quality levels of the studies were upgraded or downgraded in consideration of factors affecting the quality of the studies. The level of evidence was graded as follows: high, moderate, low, and very low.

The grade of recommendation was classified as strong or weak depending on the balance between benefit and harm of the recommendation, quality of evidence, values and preferences. A strong recommendation is directed to most patients because it has more positive than negative effects, is supported by high-quality evidence, and is highly valuable and more strongly preferred than other interventions. ${ }^{1}$ A weak recommendation is also beneficial for a lot of patients although it has relatively small positive effects and/or weak-quality evidence. In the case of a weak recommendation, an alternative intervention method can be chosen depending on values and preferences of physicians. Recommendations, grades of recommendation, and levels of evidence are summarized in Table 1.

\section{Review and approval of the guideline}

The editorial committee consisted of 34 members of the KSGE Steering Committee and 14 members from the Insurance Committee. They conducted the review of the first draft with open-ended questions. The draft was revised by the KSGE Task Force on CPG and was reviewed again by the editorial committee to ensure the completeness of the guideline. As an external review of this guideline, a public meeting was held at "KSGE Days 2019", in which endoscopists and nurses from across the country gathered on 16 November 2019. The final draft of guideline was revised and made based on the discussions during this meeting.

\section{Provision of clinical practice guideline and plans for future updates}

For wide provision and distribution of this CPG, the guideline will be co-published in Clinical Endoscopy (official journal of the KSGE) and the Korean Journal of Gastroenterology (official journal of the Korean Society of Gastroenterology). It will be posted on the website of the KSGE, and registered in the Korean Medical Guideline Information Center. Because the rapid distribution of the CPG to endoscopists through the databases is expected to be difficult, the KSGE will distribute the guideline for free through various channels including emails and will actively promote it at academic conferences, seminars, and workshops. This CPG will be revised as necessary to account for changes in technology, new data, or other aspects of clinical practice in the future.

\section{Limitations}

The most critical limitation of this CPG is the lack of local evidences in Korea. Evidences from foreign countries cannot be directly applied to the development of the guideline for the Korean population, because the risks of developing adverse events associated with endoscopic procedures and thromboembolism caused by withholding antithrombotic agents differ among countries. This CPG is not intended to provide absolute treatment standards in real clinical practice, but rather to help physicians make evidence-based clinical decisions with regard to the management of antithrombotic agents before and after endoscopic procedures. Therefore, the treatment for each patient should be finally determined by the physician considering various clinical factors of individual patients. This CPG cannot be used as a basis for health insurance to restrict physician's practice or as a basis for a legal judgment on medical practice.

\section{Editorial independence}

This CPG was selected as a project of the KSGE and received financial support from the KSGE. However, the KSGE did not affect the process of the CPG development, and all members involved in the development of the CPG had no interest or potential conflicts of interest.

\section{RISK STRATIFICATON OF PROCEDURES AND PATIENTS}

\section{Categorization of endoscopic procedures according to the risk of bleeding}

This CPG categorized endoscopic procedures into low-risk, high-risk, and ultra-high-risk procedures, according to the risk of bleeding associated with endoscopic procedures reported in patients not taking antithrombotic agents (Table 2). Lowrisk endoscopic procedures were defined as procedures where the risk of bleeding was expected to be less than $1 \%$. Those procedures included diagnostic endoscopic procedures with mucosal biopsy and therapeutic endoscopic procedures without mucosal incision. High-risk endoscopic procedures were defined as procedures where the risk of bleeding was expected to be more than $1 \%$. Among high-risk endoscopic procedures, endoscopic mucosal resection (EMR) for large colon polyp ( $\geq 2$ $\mathrm{cm}$ ) and endoscopic submucosal dissection (ESD), which are 
Table 2. Risk Stratification of Endoscopic Procedures Based on the Risk of Bleeding

\section{Low-risk procedures}

Diagnostic endoscopy including mucosal biopsy

Endoscopic ultrasonography without needle aspiration or biopsy

ERCP with stent (biliary or pancreatic) placement

Papillary balloon dilation without sphincterotomy

Diagnostic push or device-assisted enteroscopy

Video capsule endoscopy

Esophageal, gastric, enteral, and colonic stenting

\begin{tabular}{l} 
High-risk procedures \\
\hline Endoscopic polypectomy \\
ERCP with sphincterotomy \\
Dilation of gastrointestinal strictures \\
Injection or band ligation of varices \\
Percutaneous endoscopic gastrostomy or jejunostomy \\
Endoscopic ultrasonography with needle aspiration or biopsy \\
Endoscopic papillectomy \\
Cystogastrostomy \\
Ultra-high-risk procedures \\
\hline Endoscopic submucosal dissection \\
Endoscopic mucosal resection of large colon polyps $(\geq 2 \mathrm{~cm})$
\end{tabular}

ERCP, endoscopic retrograde cholangiopancreatography.

frequently performed in Asian countries, including South Korea, and which have a higher risk of bleeding compared with other high-risk endoscopic procedures, were categorized as ultra-high-risk endoscopic procedures as per the Asian Pacific Association of Gastroenterology (APAGE)/Asian Pacific Society for Digestive Endoscopy (APSDE) guideline. ${ }^{13}$

\section{Categorization of patients according to the risk of thromboembolism}

\section{Antiplatelet agents}

Patients who have undergone stent insertion due to cor- onary artery disease need to take antiplatelet agents such as aspirin or P2Y12 receptor inhibitors. Decision regarding the discontinuation of antiplatelet agents and the timing for executing high-risk endoscopic procedures should be made after comprehensive consideration of stent thrombosis, bleeding, and clinical problems that could occur secondary to delayed procedures. Nevertheless, there is limited direct evidence regarding the risk of major adverse cardiac events (MACE) such as stent thrombosis associated with endoscopic procedures in patients with coronary artery stents, and it is difficult to determine the optimal timing of procedures with a low risk of adverse events. The CPG for acute coronary syndrome proposed by the Korean Society of Interventional Cardiology in 2013 recommends consulting a cardiologist for the interruption of P2Y12 receptor inhibitors before elective non-cardiac surgery. ${ }^{19}$ Patients who have undergone drug-eluting stent insertion for unstable angina or non-ST elevation myocardial infarction are recommended to postpone surgery if 12 months have not elapsed since stent insertion. ${ }^{19}$

The CPG regarding dual antiplatelet therapy (DAPT) for coronary artery disease, which was developed by the American College of Cardiology/the American Heart Association in 2016, recommends delaying surgery for 6 months after inserting a drug-eluting stent and 30 days after inserting a bare metal stent. ${ }^{20}$ In recent large-scale case-control studies, the prevalence of MACE was $7.2 \%-11.6 \%$ when surgery was performed within 4-6 weeks of coronary stent insertion. ${ }^{21-23}$ Of note, a case-control study involving 9,391 patients showed that the type of stent was not associated with the risk of MACE. ${ }^{23}$ Based on the results of these studies, the CPG for DAPT in coronary artery disease developed by the European Society of Cardiology (ESC) in 2017 recommends delaying surgery for 4 weeks after stent insertion, regardless of the type of coronary artery stents used. ${ }^{24}$ In addition, when surgery is scheduled between 4 weeks and 6 months after stent insertion, surgery should be deferred if possible, and the decision to perform surgery should be made after considering the risks and benefits of the surgery specific to the patient. ${ }^{24}$ Based on recent studies and previously developed CPGs for the use of antithrombotic

Table 3. Appropriate Timing of High-Risk Procedures in Patients with Acute Coronary Syndrome

\begin{tabular}{|c|c|c|}
\hline Thrombotic risk & Cardiac event & Management \\
\hline Very high & PCI within 4 weeks & Defer a procedure \\
\hline High & PCI between 4 weeks and 6 months & Defer a procedure until $>6$ months after cardiac event if possible \\
\hline Moderate to low & $\begin{array}{l}\mathrm{PCI}>6 \text { months ago or stable coronary artery } \\
\text { disease }\end{array}$ & $\begin{array}{l}\text { Perform a procedure } \\
\text { Continue aspirin except in ultra-high-risk procedures } \\
\text { Withhold P2Y12 receptor inhibitors } 5-7 \text { days before the procedure }\end{array}$ \\
\hline
\end{tabular}

PCI, percutaneous coronary intervention. 
agents before and after endoscopic procedures, we have summarized the recommendations regarding the timing of highrisk endoscopic procedures in patients who have undergone coronary stent insertion (Table 3 ).

\section{Anticoagulants}

Decisions to continue or discontinue anticoagulants in patients undergoing endoscopic procedures should consider both the risk of bleeding associated with endoscopic procedures and thromboembolism caused by withholding anticoagulants. The risk of thromboembolism, which may occur due to the discontinuation of anticoagulants, is closely related to the underlying disease requiring the use of anticoagulants, and the absolute risk of thromboembolism is known to increase by approximately $1 \%$ when anticoagulants are discontinued for 4-7 days. ${ }^{25,26}$ However, most studies on the management of anticoagulants before and after endoscopic procedures are observational studies, and almost all CPGs and their recommendations are based on expert opinions. Moreover, recommendations are applied in various ways in real-world clinical practice, and there is no consensus even among experts. Regarding the risk of thromboembolism, the British Society of Gastroenterology (BSG)/European Society of Gastrointestinal Endoscopy (ESGE) guideline categorized patients into lowand high-risk groups according to the estimated annual risk of thromboembolism that may occur during anticoagulation discontinuation. ${ }^{11}$ The American Society for Gastrointestinal Endoscopy (ASGE) guideline categorized patients into three groups according to the risk of thromboembolism: low-risk $(<5 \%)$, moderate-risk (5\%-10\%), and high-risk ( $>10 \%){ }^{12}$ Based on recent studies and previously developed CPGs regarding the management of antithrombotic agents before and after endoscopic procedures, we summarized high-risk patients, for whom there is a high risk of thromboembolism when anticoagulants are withheld, requiring heparin bridging therapy (Table 4$).{ }^{11-13}$

Table 4. High-Risk Conditions for Thromboembolism Associated with Withdrawal of Anticoagulants

Nonvalvular atrial fibrillation with a $\mathrm{CHA}_{2} \mathrm{DS}_{2}$-VASc score $>5$

Prosthetic valve or mitral valve stenosis with atrial fibrillation

Prosthetic mitral valve

$<3$ months after venous thromboembolism

\section{RECOMMENDATIONS FOR THE MANAGEMENT OF ANTITHROMBOTIC AGENTS BEFORE AND AFTER ENDOSCOPIC PROCEDURES}

\author{
Statement 1: We do not recommend discontinuation \\ of antiplatelet agents before low-risk endoscopic \\ procedures in patients taking one kind of antiplatelet \\ agent (Grade of recommendation, strong; Level of \\ evidence, moderate).
}

The risk of bleeding associated with diagnostic endoscopy, including mucosal biopsy, is reported to be less than $0.1 \%$ even when an antiplatelet agent such as aspirin or clopidogrel is used. ${ }^{27-37} \mathrm{~A}$ previous prospective study reported the bleeding rate after upper gastrointestinal endoscopy, including mucosal biopsy, without withholding antiplatelet agents before the procedure, and the bleeding rates in aspirin-only and clopidogrel-only groups were $0.4 \%$ and $0.0 \%$, respectively. ${ }^{35}$ In a Japanese prospective study involving patients taking antiplatelet agents, no bleeding occurred after upper gastrointestinal endoscopy or colonoscopy including mucosal biopsy. ${ }^{34} \mathrm{An}$ other retrospective study investigated the effect of antiplatelet agents on the bleeding rate after endoscopic papillary balloon dilatation in patients taking antiplatelet agents. ${ }^{38}$ In that study, the bleeding rate was $0.8 \%$, and no increase in bleeding rate was observed in the group that continued antiplatelet agents compared to that of the group that discontinued antiplatelet agents before the procedure. These results support the recommendation not to withhold antiplatelet agents before low-risk endoscopic procedures.

\section{Statement 2: We do not recommend discontinuation of aspirin before high-risk endoscopic procedures in patients taking aspirin. For ultra-high-risk endoscopic procedures such as endoscopic mucosal resection for large colon polyps ( $\geq 2 \mathrm{~cm}$ ) and endoscopic submucosal dissection, withholding aspirin before the procedures could be considered, depending on the risk of bleeding and thromboembolism (Grade of recommendation, strong; Level of evidence, moderate).}

The prevalence of post-polypectomy bleeding (PPB) is reported to be $0.6 \%-2.2 \%{ }^{31,33,39-45}$ Case-control studies of patients undergoing colonic polypectomy reported that aspirin use did not increase the risk of PPB. ${ }^{37,46-48}$ In a Korean casecontrol study, the bleeding rate after colon polypectomy was $1.1 \%$, and the frequency of aspirin use was not different between patients with PPB $(n=92)$ and those without $(n=276){ }^{49}$ A recent meta-analysis also showed that there was no increase 
in bleeding rate associated with colon polypectomy when aspirin was not withhold before the procedure (odds ratio [OR], 1.5; 95\% confidence interval [CI], 0.9-2.2)..$^{50}$ Therefore, we recommend that patients who are taking aspirin alone do not need to withhold taking aspirin before colon polypectomy. However, if patients without underlying cardio-cerebrovascular disease are taking aspirin for primary prevention, withholding aspirin before the procedure may be considered.

The size of the colon polyp is a well-known risk factor for delayed bleeding after polypectomy. A previous study reported that the risk of delayed bleeding after colon polypectomy increased by $9 \%$ for every $1-\mathrm{mm}$ increase in polyp size. ${ }^{51} \mathrm{In}$ particular, a higher rate of PPB has been reported after EMR for large colon polyps ( $\geq 2 \mathrm{~cm}$ ). ${ }^{52-54}$ In an Australian study, the bleeding rate after EMR for large colon polyps $(\geq 2 \mathrm{~cm})$ was $7 \%$, and the use of aspirin within 7 days before the procedure was associated with an increased risk of bleeding. ${ }^{54}$ These findings suggest that discontinuation of aspirin could be considered before EMR of large colon polyps, depending on the risk of thromboembolism and procedure-related bleeding.

ESD carries a higher bleeding risk than EMR (OR, 2.20; 95\% CI, 1.58-3.07).$^{55}$ The bleeding rates after gastric and colon ESD were reported to be $3.6 \%-6.9 \%$ and $0.5 \%-9.5 \%$, respectively. ${ }^{56-64}$ While some studies reported that the risk of post-ESD bleeding was increased with persistent use of aspirin before ESD, others reported no increase in the bleeding rate regardless of aspirin discontinuation. ${ }^{56-64}$ In a Korean study that investigated the bleeding rate after gastric ESD, the bleeding rates were $11.6 \%$ and $5.9 \%$ in the antiplatelet-continuation group and the withdrawal group, respectively; however, these rates were not statistically significant. ${ }^{61}$ However, in another Korean study, the bleeding rate in the continuation group was significantly higher than that of the withdrawal group after gastric ESD (21.1\% and 3.6\%, respectively). ${ }^{56}$ Taken together, there remains controversy as to whether continuous administration of aspirin before ESD increases the risk of bleeding. Indeed, the BSG/ESGE and the APAGE/APSDE guidelines recommend withholding antithrombotic agents, including aspirin, before ESD because of the high risk of bleeding. ${ }^{12,13}$ However, because the discontinuation of aspirin in patients taking aspirin for secondary prevention could increase the risk of thromboembolism, withholding aspirin before high-risk procedures should be determined based on the risk of thromboembolism and bleeding, ideally after consultation with a cardiologist or neurologist. ${ }^{65-67}$

The bleeding rate associated with endoscopic papillary sphincterotomy (EST) has been reported to be $1 \%-5 \%$, and an increase in bleeding rate was not observed even if antiplatelet agents were not discontinued before the procedure. ${ }^{38,68-74} \mathrm{~A}$
Japanese retrospective study investigated the effect of antiplatelet agents on bleeding risk after EST in patients with choledocholithiasis. ${ }^{38}$ In that study, the bleeding rate after EST was $0.8 \%$ in both the aspirin continuation and withdrawal groups. Another retrospective study reported that the use of aspirin within 7 days before EST did not increase the risk of bleeding associated with the procedure. ${ }^{73}$

\section{Statement 3. We recommend withholding P2Y12 receptor inhibitors (clopidogrel, ticlopidine, prasugrel, and ticagrelor) 5-7 days before high-risk endoscopic procedures (Grade of recommendation, strong; Level of evidence, moderate).}

In patients taking $\mathrm{P} 2 \mathrm{Y} 12$ receptor inhibitors, the risk of bleeding can be increased during high-risk endoscopic procedures such as colon polypectomy. In a prospective study that investigated patients undergoing colon polypectomy, the bleeding rate was $2.4 \%$ in patients who continued clopidogrel or prasugrel before the procedure, compared to $0.0 \%$ in patients who had never taken clopidogrel or prasugrel, showing a significant increase of the bleeding risk in the P2Y12 receptor inhibitor continuation group. ${ }^{75}$ Recent studies including meta-analyses also reported that the continuation of clopidogrel increased the risk of bleeding after colon polypectomy (OR, 4.7; 95\% CI, 2.4-9.2).$^{50,75-77}$ Therefore, it is recommended to withdraw P2Y12 receptor inhibitors 5-7 days before colon polypectomy. The BSG/ESGE and APAGE/APSDE guidelines recommend temporary replacement with aspirin in patients who are expected to carry a higher risk of developing thromboembolism when discontinuing P2Y12 receptor inhibitors, after consultation with a neurologist or cardiologist. ${ }^{12,13}$

A recent meta-analysis based on 74 studies showed that the use of an antiplatelet agent, including P2Y12 receptor inhibitors, was associated with a significant increase in the risk of bleeding after gastric ESD (OR, 1.63; 95\% CI, 1.30-2.03). ${ }^{60}$ Otherwise, there are only a few studies regarding whether the continuation of $\mathrm{P} 2 \mathrm{Y} 12$ receptor inhibitors is associated with the risk of bleeding after other high-risk endoscopic procedures. ${ }^{71,78,79}$

\section{Statement 4. We suggest resuming P2Y12 receptor inhibitors as soon as possible once adequate hemostasis has been achieved (Grade of recommendation, weak; Level of evidence, low).}

Currently, there are no data supporting the ideal timing as to when to resume P2Y12 receptor inhibitors after high-risk endoscopic procedures. Therefore, it could be helpful to consult with a cardiologist or neurologist regarding the duration of discontinuation and the timing for resuming P2Y12 recep- 
tor inhibitors. In patients with a high risk of thromboembolism such as those undergoing coronary artery stent insertion, the risk of thromboembolism is increased if the duration of discontinuation of an antiplatelet agent is prolonged. Considering that it usually takes 3-5 days after resuming P2Y12 receptor inhibitors for the effect of the antiplatelet agent to appear, it is recommended to resume P2Y12 receptor inhibitors as soon as possible if adequate hemostasis is achieved during the procedure and there is no evidence of bleeding after the procedures. ${ }^{80}$ Because resuming P2Y12 receptor inhibitors after high-risk endoscopic procedures may increase the risk of delayed bleeding, patient education and close monitoring are warranted.

Statement 5. In patients on dual antiplatelet therapy, we do not recommend withholding both antiplatelet agents before low-risk endoscopic procedures (Grade of recommendation, weak; Level of evidence, low).

There are few studies on the risk of bleeding associated with low-risk endoscopic procedures, including mucosal biopsy, in patients on DAPT. In a Japanese prospective study that analyzed 48 upper gastrointestinal endoscopies and 12 colonoscopies in 60 patients, including a total of 101 biopsies, there was no significant bleeding during 2 weeks after endoscopy $(0 / 101$; 95\% CI, 0\%-3.6\%)..$^{34}$ In addition, the time until the bleeding stops on visual inspection after biopsy did not differ between patients taking a single antiplatelet agent and those on DAPT $(2.4 \pm 1.4$ and $2.1 \pm 2.1$, respectively). However, the results of this study should be interpreted cautiously, because it was conducted in a small number of patients and lacked information on the use of histamine- 2 receptor antagonists or proton pump inhibitors or the number of biopsies performed in each patient.

\section{Statement 6. In patients on dual antiplatelet} therapy, we recommend withholding P2Y12 receptor inhibitors 5-7 days before high-risk endoscopic procedures. For ultra-high-risk endoscopic procedures, such as endoscopic mucosal resection for large colon polyps $(\geq 2 \mathrm{~cm})$ and endoscopic submucosal dissection, withholding both antiplatelet agents before procedures could be considered depending on the risk of bleeding and thromboembolism (Grade of recommendation, strong; Level of evidence, moderate).

To determine the discontinuation of antiplatelet agents in patients on DAPT, the risk of bleeding associated with the procedure as well as the risk of thromboembolism should be considered simultaneously. In a meta-analysis of 161 patients with stent thrombosis after discontinuation of antiplatelet agents, the median time to stent thrombosis was 122 days when discontinuing P2Y12 receptor inhibitors alone and 7 days when discontinuing both aspirin and $\mathrm{P} 2 \mathrm{Y} 12$ receptor inhibitors. ${ }^{80}$ In a retrospective study of 1,385 patients undergoing colon polypectomy, the simultaneous use of aspirin and clopidogrel increased the risk of bleeding (OR, 3.7; 95\% CI, 1.6-8.5). ${ }^{77}$ In that study, the delayed PPB rates of aspirin-only and DAPT groups were $1.0 \%$ and $3.5 \%$, respectively $(p<0.02)$. A recent meta-analysis also showed that the risk of bleeding after colon polypectomy was significantly increased when aspirin and clopidogrel were used simultaneously (OR, 3.4; 95\% CI, 1.38.8). ${ }^{50}$ Therefore, we recommend withholding P2Y12 receptor inhibitors 5-7 days before the procedure in patients on DAPT, while continuing aspirin.

For ultra-high-risk endoscopic procedures, such as EMR for large colon polyps $(\geq 2 \mathrm{~cm}$ ) and ESD, the risk of bleeding associated with the procedures could be increased even when taking aspirin alone ${ }^{52-54,56}$ In a large-scale case-control study of 2,179 patients undergoing drug-eluting stent insertion in South Korea, the risk of MACE after discontinuation of both aspirin and P2Y12 receptor inhibitor was not significantly greater than that in patients who withheld only a P2Y12 receptor inhibitor, when the duration of discontinuation was less than 7 days. ${ }^{81}$ These findings suggest that, for ultra-highrisk endoscopic procedures in patients taking both aspirin and $\mathrm{P} 2 \mathrm{Y} 12$ receptor inhibitor, short-term discontinuation of the two antiplatelet agents could be considered depending on the risk of thromboembolism and bleeding after consultation with a cardiologist or neurologist.

Statement 7. In patients on dual antiplatelet therapy, we suggest resuming $\mathrm{P} 2 \mathrm{Y} 12$ receptor inhibitors as soon as possible once adequate hemostasis has been achieved (Grade of recommendation, weak; Level of evidence, low).

There are no data on the optimal timing of resuming P2Y12 receptor inhibitors after high-risk endoscopic procedures in patients on DAPT. In patients with a high risk of thromboembolism or those with coronary artery stent, it is important to recognize that the risk of thromboembolism increases as the duration of $\mathrm{P} 2 \mathrm{Y} 12$ receptor inhibitor discontinuation is prolonged. Therefore, it is recommended to restart P2Y12 receptor inhibitors as soon as possible once adequate hemostasis has been achieved and there is no evidence of further bleeding. Decisions on the duration of discontinuation and the timing for resuming P2Y12 receptor inhibitors should be individualized, and optimally after consulting a cardiologist or neurologist. In addition, since resuming of P2Y12 receptor in- 
hibitors after the procedures could increase the risk of adverse events, including delayed bleeding, particular care should be taken when resuming P2Y12 receptor inhibitors.

\section{Statement 8. We do not recommend withholding warfarin before low-risk endoscopic procedures (Grade of recommendation, weak; Level of evidence, low).}

Few studies have investigated the risk of bleeding associated with low-risk endoscopic procedures, including mucosal biopsy, in patients on warfarin. The risk of bleeding associated with mucosal biopsy is considered very low, and it is considered safe to perform endoscopic biopsy while continuing antithrombotic agents. ${ }^{31} \mathrm{~A}$ Japanese prospective study showed that there were no cases of delayed bleeding after biopsy in patients taking aspirin, clopidogrel, or warfarin, and that bleeding time after endoscopic biopsy did not differ between patients who took warfarin and those who did not. ${ }^{34}$ Considering that the sequelae of thromboembolism are significant, it is recommended to continue warfarin where possible. However, because the risk of bleeding increases when the international normalized ratio (INR) exceeds the therapeutic range, it should be ensured that the INR is maintained within the therapeutic range during the peri-endoscopic period. ${ }^{82}$ The APAGE/APSDE guideline recommends a delay of the endoscopic procedures if INR exceeds 3.5 prior to the procedures. ${ }^{13}$

\section{Statement 9. We suggest withholding warfarin} 3-5 days before high-risk endoscopic procedures. Heparin bridging therapy is recommended in patients with high thromboembolic risk (Grade of recommendation, weak; Level of evidence, low).

There are limited data on the bleeding risk associated with high-risk endoscopic procedures in patients while continuing anticoagulants, and current guidelines on the periprocedural management of anticoagulants are largely based on expert opinions. Observational studies showed that the risk of bleeding associated with high-risk endoscopic procedures was significantly higher in patients taking anticoagulants than in those not taking them. ${ }^{46,83,84}$ In a retrospective study investigating 1,657 colon polypectomies, warfarin therapy was an independent risk factor for PPB ${ }^{46}$ Previous studies have also assessed the methods to reduce the risk of bleeding associated with endoscopic resection when warfarin cannot be withheld because of a high risk of thromboembolism. When comparing cold snaring and conventional polypectomy for colon polyps less than $1 \mathrm{~cm}$ in patients without cessation of warfarin, delayed bleeding occurred in $0.0 \%$ (0/35) with cold snare pol- ypectomy and in $14 \%$ (5/35) with conventional polypectomy $(p=0.027)$, suggesting that cold snaring polypectomy can be employed in anticoagulated patients. ${ }^{85}$

The INR decreased over 24-36 hours after discontinuation of warfarin, and the INR decreased to $1.5 \mathrm{in}$ most patients after 3-5 days of warfarin discontinuation. ${ }^{86,87}$ The risk of bleeding associated with endoscopic procedures does not increase when the level of INR is 1.5 or less. Therefore, it is recommended to withhold warfarin 3-5 days before high-risk procedures, and INR before and after the procedure should be checked. Recommendations for the required level of INR before highrisk endoscopic procedures differ according to the CPGs: the APAGE/APSDE guideline suggests that the procedures can be performed when the level of INR is 2.0 or less, whereas the $\mathrm{BSG} / \mathrm{ESGE}$ guideline recommends endoscopic procedures to be undertaken if INR is below 1.5. ${ }^{12,13}$

During temporary interruption of warfarin therapy, heparin bridging therapy with unfractionated heparin or low-molecular-weight heparin is recommended in patients who are expected to have high risks of thromboembolism. The purpose of heparin bridging therapy is to reduce the risk of thromboembolism by minimizing the amount of time patients are not receiving therapeutic anticoagulation agents. The APAGE/ APSDE, ASGE, and BSG/ESGE guidelines suggest indications for patients requiring heparin bridging therapy. ${ }^{11-13}$ The guideline for stroke prevention in patients with nonvalvular atrial fibrillation proposed by the Korean Heart Rhythm Society recommends heparin bridging therapy only in patients with prosthetic valves. ${ }^{88}$ It is based on a large-scale randomized controlled trial assessing the role of heparin bridging therapy in 1,884 patients with nonvalvular atrial fibrillation who needed warfarin interruption for invasive procedure or surgery, including $44.0 \%$ of gastrointestinal procedures.$^{89}$ In that study, the incidence of arterial thromboembolism did not differ between the bridging and no bridging groups $(0.3 \%$ and $0.4 \%$, respectively), while the risk of major bleeding was significantly higher in the bridging group than in the no-bridging group (3.2\% and $1.3 \%$, respectively). However, the proportion of patients with valvular heart disease $(\leq 2 \%)$ or those with $\mathrm{CHA}_{2} \mathrm{DS}_{2}$ score of 5 or $6(\leq 3.4 \%)$ was low, suggesting that these data cannot be applied to patients with a high risk of thromboembolism. Given the lack of definitive data on optimal treatment strategies for patients who require warfarin interruption, indications for heparin bridging therapy vary according to the CPGs. We suggest an indication of heparin bridging therapy by selecting a group of patients who are expected to obtain a greater therapeutic benefit of bridging while minimizing the risk of periprocedural bleeding (Table 4). 
Statement 10. We suggest resuming warfarin as soon as possible once adequate hemostasis has been achieved (Grade of recommendation, weak; Level of evidence, low).

The timing for warfarin resumption should be determined based on both the risk of bleeding and thromboembolism. There are few studies supporting re-initiation of warfarin on the day of the procedure. In a study that analyzed 123 polypectomies for colon polyp less than $1 \mathrm{~cm}$, bleeding that required transfusions occurred only in one case $(0.8 \%)$ when resuming warfarin the day after the procedure..$^{90}$ In another study involving 109 colonoscopies, including hot biopsy and snare polypectomy, the bleeding rate associated with the procedure was $0.9 \%$ following resumption warfarin the day after the procedure. ${ }^{91}$ Conversely, a study of 173 patients who underwent colon polypectomy showed that the risk of bleeding increased by about five times when resuming warfarin within a week following polypectomy. ${ }^{51}$

Because it takes 5-7 days to reach the therapeutic range after re-administration of warfarin, we recommend early resumption of warfarin on the day of the endoscopic procedure in patients with high thromboembolic risk once adequate hemostasis has been achieved and there is no evidence of bleeding. The APAGE/APSDE guideline recommends resuming warfarin as soon as possible, and the ASGE and BSG/ESGE guidelines recommend resuming warfarin on the day of the procedure in patients with high risk for thromboembolism. ${ }^{11-13}$

\section{Statement 11. We do not recommend} discontinuation of NOAC before low-risk endoscopic procedures (Grade of recommendation, weak; Level of evidence, low).

There is no evidence as to whether it is necessary to withhold NOAC before low-risk endoscopic procedures. The risk of bleeding associated with mucosal biopsy is considered very low, and endoscopic biopsy can be performed safely in patients taking anticoagulants. ${ }^{31,92}$ The APAGE/APSDE and ASGE guidelines recommend against withholding NOAC before low-risk endoscopic procedures. ${ }^{11,13}$ This is intended to minimize the risk of thromboembolism caused by discontinuation of anticoagulants. The Japan Gastroenterological Endoscopy Society guideline also recommends not to withhold NOAC before low-risk endoscopic procedures, and to perform the procedure at a time avoiding NOAC reaching its peak blood concentration. ${ }^{93}$ In addition, they recommend minimizing the number of biopsies, confirming hemostasis before withdrawing the endoscope, and considering endoscopic hemostasis if bleeding does not stop spontaneously. By contrast, the BSG/ ESGE guideline recommends withholding NOAC on the day of conducting low-risk endoscopic procedures. ${ }^{12}$ Because the discontinuation of NOAC could increase the risk of thromboembolism, we recommend not to withhold NOAC before lowrisk endoscopic procedures.

\section{Statement 12. We recommend withholding NOAC more than 48 hours before high-risk endoscopic procedures (Grade of recommendation, strong; Level of evidence, low).}

Currently, four NOACs, including dabigatran (a thrombin inhibitor), apixaban, rivaroxaban, and edoxaban (a factor Xa inhibitor) are available in South Korea. There is no clear evidence as to whether it is necessary to withhold NOAC before high-risk endoscopic procedures. The Korean Heart Rhythm Society guideline recommends withholding NOAC at least 48 $\mathrm{hr}$ before invasive procedures, such as endoscopic procedures with a high risk of bleeding. ${ }^{94}$ The APAGE/APSDE and BSG/ ESGE guidelines also recommend withholding NOAC before high-risk procedures. ${ }^{12,13}$ NOACs are characterized by rapid onset (1-4 hr) and offset (about $24 \mathrm{hr}$ ) of action. Because the half-life of NOAC is about $12 \mathrm{hr}$, it is predicted that NOAC levels will be almost undetectable after $48 \mathrm{hr}$. However, the metabolism of NOAC is affected by renal function. In particular, for dabigatran, about $80 \%$ of the drug is eliminated by the kidneys, and elimination is affected by renal function decline. ${ }^{95}$ Therefore, special attention is needed for the management of NOAC in the context of impaired renal function. ${ }^{96}$ In patients with normal creatinine clearance $(\mathrm{CrCl})$, it is recommended to withhold NOAC in the 2 days preceding high-risk endoscopic procedures. For dabigatran, the duration of discontinuation before the procedure should be determined based on renal function: withhold for 3 days before the procedures if the $\mathrm{CrCl}$ is $50-80 \mathrm{~mL} / \mathrm{min}$ and for 4 days before the procedures if the $\mathrm{CrCl}$ is $30-50 \mathrm{~mL} / \mathrm{min} .{ }^{97}$ In brief, in patients using NOAC, renal function testing is required before high-risk procedures.

There is no evidence to support heparin bridging therapy in patients taking NOAC. The ASGE guideline recommends heparin bridging therapy only when NOAC cannot be resumed within $24 \mathrm{hr}$ after endoscopic procedures. ${ }^{11}$ Neither the APAGE/APSDE nor the BSG/ESGE recommends heparin bridging therapy during discontinuation of NOAC, based on its rapid onset of action. ${ }^{12,13}$ The Korean Heart Rhythm Society also does not recommend heparin bridging therapy during temporary cessation of NOAC, because the anticoagulation effect of NOAC is predictable. ${ }^{94}$

Statement 13. We suggest resuming NOAC once adequate hemostasis has been achieved (Grade of recommendation, weak; Level of evidence, low). 
There are no data regarding the optimal timing of resuming NOAC after high-risk endoscopic procedures. Therefore, if necessary, it is best to consult with a cardiologist or neurologist regarding the duration of discontinuation and the timing for resumption of NOAC. The CPG of the APAGE/APSDE recommends early resumption of NOAC to minimize the risk of thromboembolism. ${ }^{13}$ In contrast, the BSG/ESGE recommends resuming NOAC 24-48 hr after high-risk endoscopic procedures, considering bleeding risk and the rapid onset of action of NOAC. ${ }^{12}$ Given that the longer duration of discontinuation of NOAC could increase the risk of thromboembolism, we recommend early resumption of NOAC once endoscopic hemostasis is achieved and there is no evidence of further bleeding.

\section{CONCLUSIONS}

The incidence of cardio-cerebrovascular disease is increasing with the aging of the population. This has led to an increase in the number of patients taking antithrombotic agents. The risk of bleeding varies according to the endoscopic procedures, and the use of antithrombotic agents could further increase the risk of such adverse events. To determine whether and when to withhold the use of antithrombotic agents before endoscopic procedures, the risk of thromboembolism caused by withholding of antithrombotic agents and the risk of bleeding associated with endoscopic procedures should be simultaneously considered. This CPG is intended to assist gastroenterologists who perform endoscopic procedures in decision-making and to provide a standard to guide clinical practice regarding the use of antithrombotic agents before and after endoscopic procedures. This guideline is expected to improve the safety and effectiveness of endoscopic procedures by minimizing adverse events such as bleeding and thromboembolism in patients using antithrombotic agents.

\section{Conflicts of Interest}

The authors have no financial conflicts of interest.

\section{Acknowledgement}

We would like to express our gratitude to Dr. Miyoung Choi, a CPG development methodology expert from the Korean National Evidence-based Healthcare Collaborating Agency, who has provided invaluable advice for the development of the CPG.

\section{Author Contributions}

Conceptualization: Jeong-Sik Byeon, Chan Guk Park, Joo Young Cho, Soo Teik Lee, Ho Gak Kim, Hoon Jai Chun

Data curation: Hyun Lim, Eun Jeong Gong, Byung-Hoon Min, Seung Joo Kang, Cheol Min Shin, Miyoung Choi

Formal analysis: HL, EJG, BHM, SJK, CMS
Methodology: MC

Supervision: BHM, JSB, CGP, JYC, STL, HGK, HJC

Validation: JSB

Writing-original draft: HL, EJG, SJK, CMS

Writing-review\&editing: HL, EJG, BHM, SJK, CMS

ORCID

Hyun Lim: https://orcid.org/0000-0001-6581-6420

Eun Jeong Gong: https://orcid.org/0000-0003-3996-3472

Byung-Hoon Min: https://orcid.org/0000-0001-8048-361X

Jeong-Sik Byeon: https://orcid.org/0000-0002-9793-6379

Miyoung Choi: https://orcid.org/0000-0002-2424-9965

Chan Guk Park: https://orcid.org/0000-0002-9581-2655

Joo Young Cho: https://orcid.org/0000-0002-7182-5806

Soo Teik Lee: https://orcid.org/0000-0002-0758-1923

Ho Gak Kim: https://orcid.org/0000-0003-3365-1662

Hoon Jai Chun: https://orcid.org/0000-0002-5539-361X

\section{REFERENCES}

1. Antithrombotic Trialists' Collaboration. Collaborative meta-analysis of randomised trials of antiplatelet therapy for prevention of death, myocardial infarction, and stroke in high risk patients. BMJ 2002;324:71-86.

2. Antithrombotic Trialists' (ATT) Collaboration; Baigent C, Blackwell $\mathrm{L}$, et al. Aspirin in the primary and secondary prevention of vascular disease: collaborative meta-analysis of individual participant data from randomised trials. Lancet 2009;373:1849-1860.

3. Boston Area Anticoagulation Trial for Atrial Fibrillation Investigators; Singer DE, Hughes RA, et al. The effect of low-dose warfarin on the risk of stroke in patients with nonrheumatic atrial fibrillation. N Engl J Med 1990;323:1505-1511

4. van Walraven C, Hart RG, Singer DE, et al. Oral anticoagulants vs aspirin in nonvalvular atrial fibrillation: an individual patient meta-analysis. JAMA 2002;288:2441-2448.

5. Choi KS, Jung HY, Choi KD, et al. EMR versus gastrectomy for intramucosal gastric cancer: comparison of long-term outcomes. Gastrointest Endosc 2011;73:942-948.

6. Pyo JH, Lee $\mathrm{H}, \mathrm{Min} \mathrm{BH}$, et al. Long-term outcome of endoscopic resection vs. surgery for early gastric cancer: a non-inferiority-matched cohort study. Am J Gastroenterol 2016;111:240-249.

7. Kim YG, Kong SH, Oh SY, et al. Effects of screening on gastric cancer management: comparative analysis of the results in 2006 and in 2011. J Gastric Cancer 2014;14:129-134.

8. Holbrook A, Schulman S, Witt DM, et al. Evidence-based management of anticoagulant therapy: antithrombotic therapy and prevention of thrombosis, 9th ed: American College of Chest Physicians evidence-based clinical practice guidelines. Chest 2012;141(2 Suppl):e152S-e184S.

9. Becker RC, Scheiman J, Dauerman HL, et al. Management of platelet-directed pharmacotherapy in patients with atherosclerotic coronary artery disease undergoing elective endoscopic gastrointestinal procedures. J Am Coll Cardiol 2009;54:2261-2276.

10. Fujimoto K, Fujishiro M, Kato M, et al. Guidelines for gastroenterological endoscopy in patients undergoing antithrombotic treatment. Dig Endosc 2014;26:1-14.

11. ASGE Standards of Practice Committee; Acosta RD, Abraham NS, et al. The management of antithrombotic agents for patients undergoing GI endoscopy. Gastrointest Endosc 2016;83:3-16.

12. Veitch AM, Vanbiervliet G, Gershlick AH, et al. Endoscopy in patients on antiplatelet or anticoagulant therapy, including direct oral anticoagulants: British Society of Gastroenterology (BSG) and European Society of Gastrointestinal Endoscopy (ESGE) guidelines. Gut 2016;65:374-389. 
13. Chan FKL, Goh KL, Reddy N, et al. Management of patients on antithrombotic agents undergoing emergency and elective endoscopy: joint Asian Pacific Association of Gastroenterology (APAGE) and Asian Pacific Society for Digestive Endoscopy (APSDE) practice guidelines. Gut 2018;67:405-417.

14. Brouwers MC, Kho ME, Browman GP, et al. AGREE II: advancing guideline development, reporting and evaluation in health care. CMAJ 2010;182:E839-E842.

15. Higgins JPT, Altman DG, Sterne JAC. Chapter 8: assessing risk of bias in included studies. In: Higgins JPT, Green S, eds. Cochrane handbook for systematic reviews of interventions. Version 5.1.0 [Internet]. London: Cochrane; c2011 [updated 2011 Mar]. Available from: http://handbook-5-1.cochrane.org/.

16. Sterne JA, Hernán MA, Reeves BC, et al. ROBINS-I: a tool for assessing risk of bias in non-randomised studies of interventions. BMJ 2016;355:14919.

17. Shea BJ, Grimshaw JM, Wells GA, et al. Development of AMSTAR: a measurement tool to assess the methodological quality of systematic reviews. BMC Med Res Methodol 2007;7:10.

18. Guyatt GH, Oxman AD, Kunz R, et al. Incorporating considerations of resources use into grading recommendations. BMJ 2008;336:1170-1173.

19. Ischemic Heart Disease Clinical Research Center. Recommendation for standard treatment for acute coronary syndrome [Internet]. Seoul: Korean Society of Cardiology; c2013 [updated 2013 Mar 12; cited 2020 Jul 15]. Available from: https://www.circulation.or.kr:4443/bbs/index. php ?code $=\mathrm{m} \_$info\&category $=$\&gubun $=$\&page $=1$ \& number $=263 \&$ mode $=$ view\&keyfield $=\& k e y=$.

20. Levine GN, Bates ER, Bittl JA, et al. 2016 ACC/AHA guideline focused update on duration of dual antiplatelet therapy in patients with coronary artery disease: a report of the American College of Cardiology/American Heart Association Task Force on clinical practice guidelines: an update of the $2011 \mathrm{ACCF} / \mathrm{AHA} / \mathrm{SCAI}$ guideline for percutaneous coronary intervention, $2011 \mathrm{ACCF} / \mathrm{AHA}$ guideline for coronary artery bypass graft surgery, 2012 ACC/AHA/ACP/AATS/PCNA/SCAI/STS guideline for the diagnosis and management of patients with stable ischemic heart disease, $2013 \mathrm{ACCF} / \mathrm{AHA}$ guideline for the management of ST-elevation myocardial infarction, 2014 AHA/ACC guideline for the management of patients with non-ST-elevation acute coronary syndromes, and 2014 ACC/AHA guideline on perioperative cardiovascular evaluation and management of patients undergoing noncardiac surgery. Circulation 2016;134:e123-e155.

21. Egholm G, Kristensen SD, Thim T, et al. Risk associated with surgery within 12 months after coronary drug-eluting stent implantation. J Am Coll Cardiol 2016;68:2622-2632.

22. Hawn MT, Graham LA, Richman JS, Itani KM, Henderson WG, Maddox TM. Risk of major adverse cardiac events following noncardiac surgery in patients with coronary stents. JAMA 2013;310:1462-1472.

23. Holcomb CN, Graham LA, Richman JS, Itani KM, Maddox TM, Hawn MT. The incremental risk of coronary stents on postoperative adverse events: a matched cohort study. Ann Surg 2016;263:924-930.

24. Valgimigli M, Bueno H, Byrne RA, et al. 2017 ESC focused update on dual antiplatelet therapy in coronary artery disease developed in collaboration with EACTS: The Task Force for dual antiplatelet therapy in coronary artery disease of the European Society of Cardiology (ESC) and of the European Association for Cardio-Thoracic Surgery (EACTS). Eur Heart J 2018;39:213-260.

25. Garcia DA, Regan S, Henault LE, et al. Risk of thromboembolism with short-term interruption of warfarin therapy. Arch Intern Med 2008;168:63-69.

26. Blacker DJ, Wijdicks EF, McClelland RL. Stroke risk in anticoagulated patients with atrial fibrillation undergoing endoscopy. Neurology 2003;61:964-968.

27. Cappell MS, Abdullah M. Management of gastrointestinal bleeding induced by gastrointestinal endoscopy. Gastroenterol Clin North Am
2000;29:125-167, vi-vii.

28. Macrae FA, Tan KG, Williams CB. Towards safer colonoscopy: a report on the complications of 5000 diagnostic or therapeutic colonoscopies. Gut 1983;24:376-383.

29. Rogers BH, Silvis SE, Nebel OT, Sugawa C, Mandelstam P. Complications of flexible fiberoptic colonoscopy and polypectomy. Gastrointest Endosc 1975;22:73-77.

30. Vu CK, Korman MG, Bejer I, Davis S. Gastrointestinal bleeding after cold biopsy. Am J Gastroenterol 1998;93:1141-1143.

31. Wexner SD, Garbus JE, Singh JJ. A prospective analysis of 13,580 colonoscopies. Reevaluation of credentialing guidelines. Surg Endosc 2001;15:251-261

32. Parra-Blanco A, Kaminaga N, Kojima T, et al. Hemoclipping for postpolypectomy and postbiopsy colonic bleeding. Gastrointest Endosc 2000;51:37-41.

33. Sieg A, Hachmoeller-Eisenbach U, Eisenbach T. Prospective evaluation of complications in outpatient GI endoscopy: a survey among German gastroenterologists. Gastrointest Endosc 2001;53:620-627.

34. Ono S, Fujishiro M, Kodashima S, et al. Evaluation of safety of endoscopic biopsy without cessation of antithrombotic agents in Japan. J Gastroenterol 2012;47:770-774.

35. Whitson MJ, Dikman AE, von Althann C, et al. Is gastroduodenal biopsy safe in patients receiving aspirin and clopidogrel?: a prospective, randomized study involving 630 biopsies. J Clin Gastroenterol 2011;45:228233.

36. Ono S, Fujishiro M, Hirano K, et al. Retrospective analysis on the management of anticoagulants and antiplatelet agents for scheduled endoscopy. J Gastroenterol 2009;44:1185-1189.

37. Shiffman ML, Farrel MT, Yee YS. Risk of bleeding after endoscopic biopsy or polypectomy in patients taking aspirin or other NSAIDS. Gastrointest Endosc 1994;40:458-462.

38. Hamada T, Yasunaga H, Nakai $Y$, et al. Bleeding after endoscopic sphincterotomy or papillary balloon dilation among users of antithrombotic agents. Endoscopy 2015;47:997-1004.

39. Bowles CJ, Leicester R, Romaya C, Swarbrick E, Williams CB, Epstein O. A prospective study of colonoscopy practice in the UK today: are we adequately prepared for national colorectal cancer screening tomorrow? Gut 2004;53:277-283.

40. Gavin DR, Valori RM, Anderson JT, Donnelly MT, Williams JG, Swarbrick ET. The national colonoscopy audit: a nationwide assessment of the quality and safety of colonoscopy in the UK. Gut 2013;62:242-249.

41. Choung BS, Kim SH, Ahn DS, et al. Incidence and risk factors of delayed postpolypectomy bleeding: a retrospective cohort study. J Clin Gastroenterol 2014;48:784-789.

42. Kim JH, Lee HJ, Ahn JW, et al. Risk factors for delayed post-polypectomy hemorrhage: a case-control study. J Gastroenterol Hepatol 2013;28:645-649

43. Manocha D, Singh M, Mehta N, Murthy UK. Bleeding risk after invasive procedures in aspirin/NSAID users: polypectomy study in veterans. Am J Med 2012;125:1222-1227.

44. Repici A, Hassan C, Vitetta E, et al. Safety of cold polypectomy for $<10 \mathrm{~mm}$ polyps at colonoscopy: a prospective multicenter study. Endoscopy 2012;44:27-31.

45. Rutter MD, Nickerson C, Rees CJ, Patnick J, Blanks RG. Risk factors for adverse events related to polypectomy in the English bowel cancer screening programme. Endoscopy 2014;46:90-97.

46. Hui AJ, Wong RM, Ching JY, Hung LC, Chung SC, Sung JJ. Risk of colonoscopic polypectomy bleeding with anticoagulants and antiplatelet agents: analysis of 1657 cases. Gastrointest Endosc 2004;59:44-48.

47. Yousfi M, Gostout CJ, Baron TH, et al. Postpolypectomy lower gastrointestinal bleeding: potential role of aspirin. Am J Gastroenterol 2004;99:1785-1789.

48. Lee SH, Shin SJ, Park DI, et al. Korean guideline for colonoscopic polypectomy. Clin Endosc 2012;45:11-24. 
49. Moon HS, Park SW, Kim DH, Kang SH, Sung JK, Jeong HY. Only the size of resected polyps is an independent risk factor for delayed postpolypectomy hemorrhage: a 10-year single-center case-control study. Ann Coloproctol 2014;30:182-185.

50. Shalman D, Gerson LB. Systematic review with meta-analysis: the risk of gastrointestinal haemorrhage post-polypectomy in patients receiving anti-platelet, anti-coagulant and/or thienopyridine medications. Aliment Pharmacol Ther 2015;42:949-956.

51. Sawhney MS, Salfiti N, Nelson DB, Lederle FA, Bond JH. Risk factors for severe delayed postpolypectomy bleeding. Endoscopy 2008;40:115119.

52. Bahin FF, Naidoo M, Williams SJ, et al. Prophylactic endoscopic coagulation to prevent bleeding after wide-field endoscopic mucosal resection of large sessile colon polyps. Clin Gastroenterol Hepatol 2015;13:724730.e1-e2.

53. Burgess NG, Metz AJ, Williams SJ, et al. Risk factors for intraprocedural and clinically significant delayed bleeding after wide-field endoscopic mucosal resection of large colonic lesions. Clin Gastroenterol Hepatol 2014;12:651-661.e1-e3.

54. Metz AJ, Bourke MJ, Moss A, Williams SJ, Swan MP, Byth K. Factors that predict bleeding following endoscopic mucosal resection of large colonic lesions. Endoscopy 2011;43:506-511.

55. Cao Y, Liao C, Tan A, Gao Y, Mo Z, Gao F. Meta-analysis of endoscopic submucosal dissection versus endoscopic mucosal resection for tumors of the gastrointestinal tract. Endoscopy 2009;41:751-757.

56. Cho SJ, Choi IJ, Kim CG, et al. Aspirin use and bleeding risk after endoscopic submucosal dissection in patients with gastric neoplasms. Endoscopy 2012;44:114-121.

57. Dong J, Wei K, Deng J, et al. Effects of antithrombotic therapy on bleeding after endoscopic submucosal dissection. Gastrointest Endosc 2017;86:807-816.

58. Koh R, Hirasawa K, Yahara S, et al. Antithrombotic drugs are risk factors for delayed postoperative bleeding after endoscopic submucosal dissection for gastric neoplasms. Gastrointest Endosc 2013;78:476-483.

59. Kono Y, Obayashi Y, Baba Y, et al. Postoperative bleeding risk after gastric endoscopic submucosal dissection during antithrombotic drug therapy. J Gastroenterol Hepatol 2018;33:453-460.

60. Libânio D, Costa MN, Pimentel-Nunes P, Dinis-Ribeiro M. Risk factors for bleeding after gastric endoscopic submucosal dissection: a systematic review and meta-analysis. Gastrointest Endosc 2016;84:572-586.

61. Lim JH, Kim SG, Kim JW, et al. Do antiplatelets increase the risk of bleeding after endoscopic submucosal dissection of gastric neoplasms? Gastrointest Endosc 2012;75:719-727.

62. Sanomura Y, Oka S, Tanaka S, et al. Continued use of low-dose aspirin does not increase the risk of bleeding during or after endoscopic submucosal dissection for early gastric cancer. Gastric Cancer 2014;17:489-496.

63. Arimoto J, Higurashi T, Chiba $\mathrm{H}$, et al. Continued use of a single antiplatelet agent does not increase the risk of delayed bleeding after colorectal endoscopic submucosal dissection. Dig Dis Sci 2018;63:218-227.

64. Ninomiya Y, Oka S, Tanaka S, et al. Risk of bleeding after endoscopic submucosal dissection for colorectal tumors in patients with continued use of low-dose aspirin. J Gastroenterol 2015;50:1041-1046.

65. Biondi-Zoccai GG, Lotrionte M, Agostoni P, et al. A systematic review and meta-analysis on the hazards of discontinuing or not adhering to aspirin among 50,279 patients at risk for coronary artery disease. Eur Heart J 2006;27:2667-2674

66. Maulaz AB, Bezerra DC, Michel P, Bogousslavsky J. Effect of discontinuing aspirin therapy on the risk of brain ischemic stroke. Arch Neurol 2005;62:1217-1220.

67. Oscarsson A, Gupta A, Fredrikson M, et al. To continue or discontinue aspirin in the perioperative period: a randomized, controlled clinical trial. Br J Anaesth 2010;104:305-312.

68. Cotton PB, Lehman G, Vennes J, et al. Endoscopic sphincterotomy complications and their management: an attempt at consensus. Gastrointest
Endosc 1991;37:383-393.

69. Freeman ML, Nelson DB, Sherman S, et al. Complications of endoscopic biliary sphincterotomy. N Engl J Med 1996;335:909-918.

70. Hui CK, Lai KC, Yuen MF, Wong WM, Lam SK, Lai CL. Does withholding aspirin for one week reduce the risk of post-sphincterotomy bleeding? Aliment Pharmacol Ther 2002;16:929-936.

71. Hussain N, Alsulaiman R, Burtin P, et al. The safety of endoscopic sphincterotomy in patients receiving antiplatelet agents: a case-control study. Aliment Pharmacol Ther 2007;25:579-584.

72. Onal IK, Parlak E, Akdogan M, et al. Do aspirin and non-steroidal anti-inflammatory drugs increase the risk of post-sphincterotomy hemorrhage--a case-control study. Clin Res Hepatol Gastroenterol 2013;37:171-176.

73. Nelson DB, Freeman ML. Major hemorrhage from endoscopic sphincterotomy: risk factor analysis. J Clin Gastroenterol 1994;19:283-287.

74. Hwang JH, Kang DH, Kim HW, Choi CW, Park SB. [The safety of endoscopic sphincterotomy in patients taking aspirin]. Korean J Med 2011;81:193-198.

75. Feagins LA, Iqbal R, Harford WV, et al. Low rate of postpolypectomy bleeding among patients who continue thienopyridine therapy during colonoscopy. Clin Gastroenterol Hepatol 2013;11:1325-1332.

76. Gandhi S, Narula N, Mosleh W, Marshall JK, Farkouh M. Meta-analysis: colonoscopic post-polypectomy bleeding in patients on continued clopidogrel therapy. Aliment Pharmacol Ther 2013;37:947-952.

77. Singh M, Mehta N, Murthy UK, Kaul V, Arif A, Newman N. Postpolypectomy bleeding in patients undergoing colonoscopy on uninterrupted clopidogrel therapy. Gastrointest Endosc 2010;71:998-1005.

78. Lee MG, Kim J, Lee SH, et al. Effect of sustained use of platelet aggregation inhibitors on post-endoscopic sphincterotomy bleeding. Dig Endosc 2014;26:737-744.

79. Oh S, Kim SG, Kim J, et al. Continuous use of thienopyridine may be as safe as low-dose aspirin in endoscopic resection of gastric tumors. Gut Liver 2018;12:393-401.

80. Eisenberg MJ, Richard PR, Libersan D, Filion KB. Safety of short-term discontinuation of antiplatelet therapy in patients with drug-eluting stents. Circulation 2009;119:1634-1642.

81. Hong SJ, Kim MJ, Kim JS, et al. Effect of perioperative antiplatelet therapy on outcomes in patients with drug-eluting stents undergoing elective noncardiac surgery. Am J Cardiol 2019;123:1414-1421.

82. Choudari CP, Rajgopal C, Palmer KR. Acute gastrointestinal haemorrhage in anticoagulated patients: diagnoses and response to endoscopic treatment. Gut 1994;35:464-466.

83. Igarashi K, Takizawa K, Kakushima N, et al. Should antithrombotic therapy be stopped in patients undergoing gastric endoscopic submucosal dissection? Surg Endosc 2017;31:1746-1753.

84. Witt DM, Delate T, McCool KH, et al. Incidence and predictors of bleeding or thrombosis after polypectomy in patients receiving and not receiving anticoagulation therapy. J Thromb Haemost 2009;7:19821989.

85. White RH, McKittrick T, Hutchinson R, Twitchell J. Temporary discontinuation of warfarin therapy: changes in the international normalized ratio. Ann Intern Med 1995;122:40-42.

86. Schulman S, Elbazi R, Zondag M, O’Donnell M. Clinical factors influencing normalization of prothrombin time after stopping warfarin: a retrospective cohort study. Thromb J 2008;6:15.

87. Horiuchi A, Nakayama Y, Kajiyama M, Tanaka N, Sano K, Graham DY. Removal of small colorectal polyps in anticoagulated patients: a prospective randomized comparison of cold snare and conventional polypectomy. Gastrointest Endosc 2014;79:417-423.

88. Joung B, Lee JM, Lee KH, et al. 2018 Korean guideline of atrial fibrillation management. Korean Circ J 2018;48:1033-1080.

89. Douketis JD, Spyropoulos AC, Kaatz S, et al. Perioperative bridging anticoagulation in patients with strial fibrillation. $N$ Engl J Med 2015;373:823-833. 
90. Friedland S, Sedehi D, Soetikno R. Colonoscopic polypectomy in anticoagulated patients. World J Gastroenterol 2009;15:1973-1976.

91. Timothy SK, Hicks TC, Opelka FG, Timmcke AE, Beck DE. Colonoscopy in the patient requiring anticoagulation. Dis Colon Rectum 2001;44:1845-1848; discussion, 1848-1849.

92. Ara N, Iijima K, Maejima R, et al. Prospective analysis of risk for bleeding after endoscopic biopsy without cessation of antithrombotics in Japan. Dig Endosc 2015;27:458-464.

93. Kato M, Uedo N, Hokimoto S, et al. Guidelines for gastroenterological endoscopy in patients undergoing antithrombotic treatment: 2017 appendix on anticoagulants including direct oral anticoagulants. Dig Endosc 2018;30:433-440

94. Lee JH, Lim HE, Lim WH, et al. The 2018 Korean heart rhythm society practical guidelines on the use of non-vitamin $\mathrm{K}$-antagonist oral anticoagulants: bleeding control and perioperative management. Korean J Med 2019;94:40-56.

95. Trocóniz IF, Tillmann C, Liesenfeld KH, Schäfer HG, Stangier J. Population pharmacokinetic analysis of the new oral thrombin inhibitor dabigatran etexilate (BIBR 1048) in patients undergoing primary elective total hip replacement surgery. J Clin Pharmacol 2007;47:371-382.

96. Heidbuchel H, Verhamme P, Alings M, et al. Updated European Heart Rhythm Association practical guide on the use of non-vitamin-K antagonist anticoagulants in patients with non-valvular atrial fibrillation: executive summary. Eur Heart J 2017;38:2137-2149.

97. Dunn A. Perioperative management of oral anticoagulation: when and how to bridge. J Thromb Thrombolysis 2006;21:85-89. 